\title{
ALFOMBRAS DE VERANO: PAVIMENTOS DE AZULEJOS DEL SIGLO XIX
}

\author{
SUMMER CARPETS: TLE PAVEMENTS FROM THE 19THCENTURY
}

\author{
Beatriu Navarro i Buenaventura
Historiadora de l'Art \\ beatriu.navarro@gmail.com \\ Josep Lluís Cebrián i Molina \\ Historiador de l'Art \\ Josep.Lluis.Cebrian@uv.es
}

\section{RESUMEN:}

Presentamos un conjunto de pavimentos de azulejos elaborados en las fábricas de València. Se trata de una tipología de la azulejería valenciana que gozó de un notable éxito a lo largo del siglo XIX. Se localizan en diferentes ciudades instalados en los salones de grandes palacios, en las residencias de la burguesía o en edificios religiosos. Algunos de los artistas más importantes del momento -Joan Bru, Josep Sanchis, Miquel Mollà o Francesc Dasí- pintaron excelentes composiciones que aún hoy se conservan. Muchos pavimentos permanecen todavía en el anonimato mientras otros han desaparecido para siempre.

\section{PALABRAS CLAVE:}

Palabras clave: Azulejo, Pavimento, Pintura cerámica, Siglo XIX, València.

\section{ABSTRACT:}

We present a set of tile pavements elaborated during the 19 th century in the factories of València. It is a typology of the Valencian tile industry that enjoyed a remarkable success. The floors are located in different cities, in palaces or residences of the bourgeoisie and religious buildings. Same of the most important artists of the moment-Joan Bru, Josep Sanchis, Miquel Mollà or Francesc Dasi- painted excellent compositions that are still preserved today. Many pavements remain anonymous while others have disappeared forever.

\section{KEY WORDS:}

Glazed tiles, Pavement, Ceramic painting, Nineteenth century, València.

\section{SUMARIO:}

Catifes d'estiu: paviments de taulells del segle XIX 


\section{CATIFES D'ESTIU: PAVIMENTS DE TAULELLS DEL SEGLE XIX}

Durant els segles XVIII i XIX assistim a un ressorgiment de l'ús de rajola vidriada i decorada per als sòls que des de l'edat mitjana no s'havia vist a les nostres terres. Mentre que al segle XV les estances pavimentades amb taulells de Manises - entre altres centres productors- oferien tot un seguit de peces de mostra caracteritzades per la pigmentació blava del cobalt, combinades en ocasions amb rajola bescuitada, ara la característica principal és la policromia. Els paviments tenen colors assortits a partir de diversos òxids utilitzats en la seua decoració, com el groc d'antimoni, el morat de manganès, el verd de coure, el marró de ferro, etc., tot amb gradacions i aiguades superposades per tal de multiplicar l'efecte cromàtic. Una altra particularitat que diferencia els paviments del segle XIX és la temàtica. Si bé en trobem nombrosos elaborats a base de taulells de mostra, hem d'afegir la innovació que suposa la tria per part del propietari de l'edifici d'un contingut iconogràfic específic, fet que implica un projecte previ, que ens ha llegat composicions úniques i exclusives en bastants casos. Així, hi trobem temes mitològics, paisat-

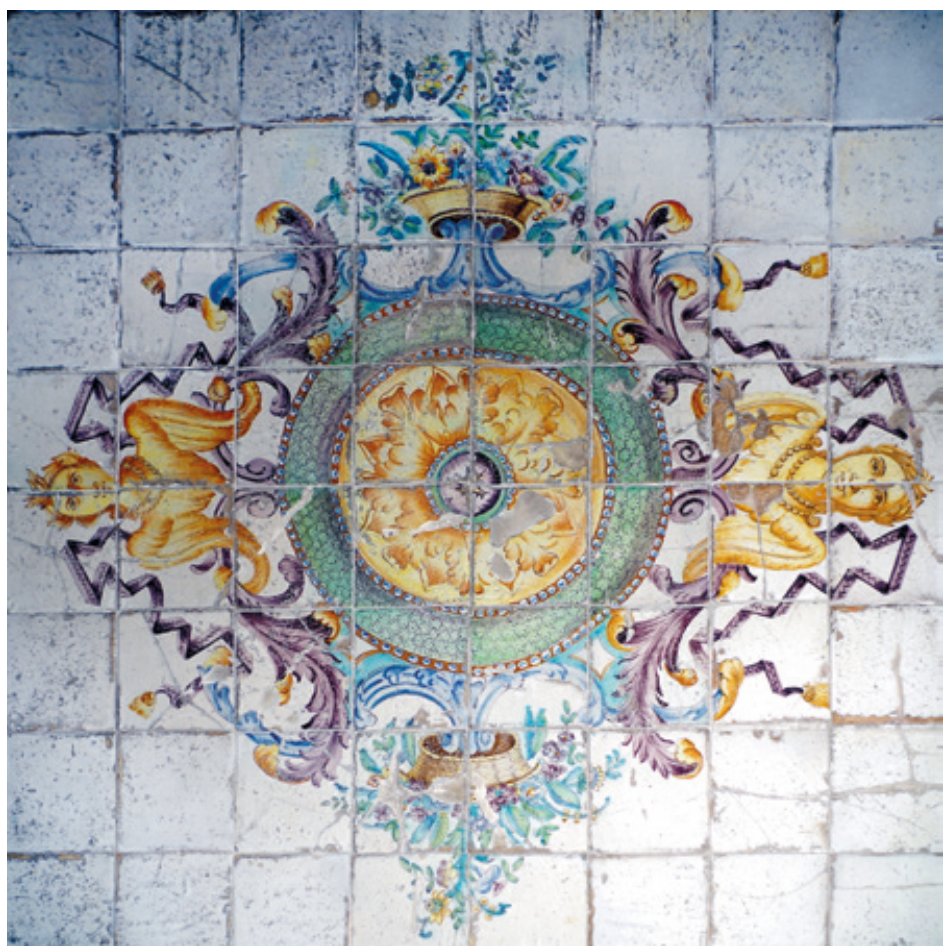

Fig. 1: Paviment de la sagristia del monestir de Portacoeli, Serra. gístics, costumistes, heràldics, natures mortes, escenes literàries, al-legories - de les estacions, de les arts, dels continents-, o temes purament ornamentals.

El clima coster de la zona mediterrània és propici per a aquest tipus de paviment ceràmic, puix la mar tempera els contrasts tèrmics proporcionant estius càlids i hiverns suaus, de manera que els paviments elaborats als forns de València gaudiren d'un èxit extraordinari durant les centúries anteriors. Eren denominats catifes d'estiu, és a dir, paviments de rajoles pintades i envernissades que en retirar les catifes tèxtils d'hivern, o les estores de trama vegetal com la palma o l'espart, permetien seguir gaudint d'una ornamentació luxosa al temps que oferia frescor. Aquesta denominació ja ens la proporciona Esclapés quan el 1737 escriu a propòsit dels avenços de les fàbriques ceràmiques de la ciutat de València i ens informa que s'havia aconseguit fer catifes com les que es fabricaven a Mesina: "se logra al presente hazer alfombras à imitación de las de Mecina, tapices, arrimadillos à modo de la China, quadros, i figuras naturales..." (Esclapés, 1738: 174-175).

La instal-lació d'un paviment constituïa una tasca complexa. En la majoria dels casos es tractava d'obres fetes ex profés en funció de la forma i les dimensions de l'espai on anava destinat i del gust del comitent. Els pintors i dissenyadors que intervenien en la confecció no seguien el procés posterior una vegada l'encàrrec eixia de la fàbrica, de manera que el client es podia desorientar a l'hora de manar obrar-lo adequadament i en l'ordre correcte. Afortunadament tenim cons tància del procediment que se seguia. Marc Antoni Disdier serví des dels seus forns de València un paviment fet a mida destinat a l'aula capitular de la catedral de Santa Anna de Las Palmas de Gran Canària, que encara podem admirar in situ. La tramesa anava acompanyada d'una carta manuscrita amb les instruc-
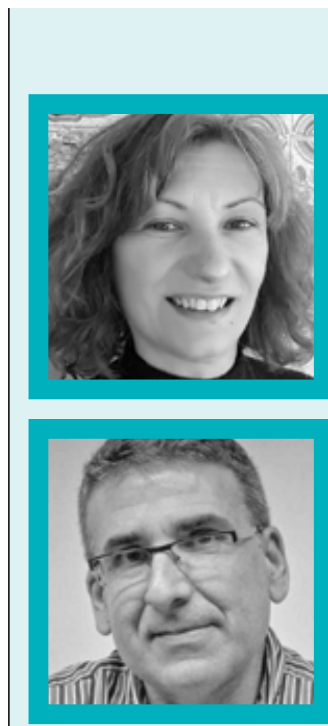

\section{Nota biogràfica:}

Beatriu Navarro i Josep Lluís Cebrián són Ilicenciats en Geografia i Història, especialitat en Història de l'Art per la Universitat de València. També són especialistes en pintura valenciana sobre taula dels segles XV-XVI i en taulelleria valenciana del segle XVIII i XIX.

\section{Beatriu Navarro:}

https://orcid.org/0000. 0003-4747-5858

Josep Lluís Cebrián: https://orcid.org/0000 0002.7809-5316 


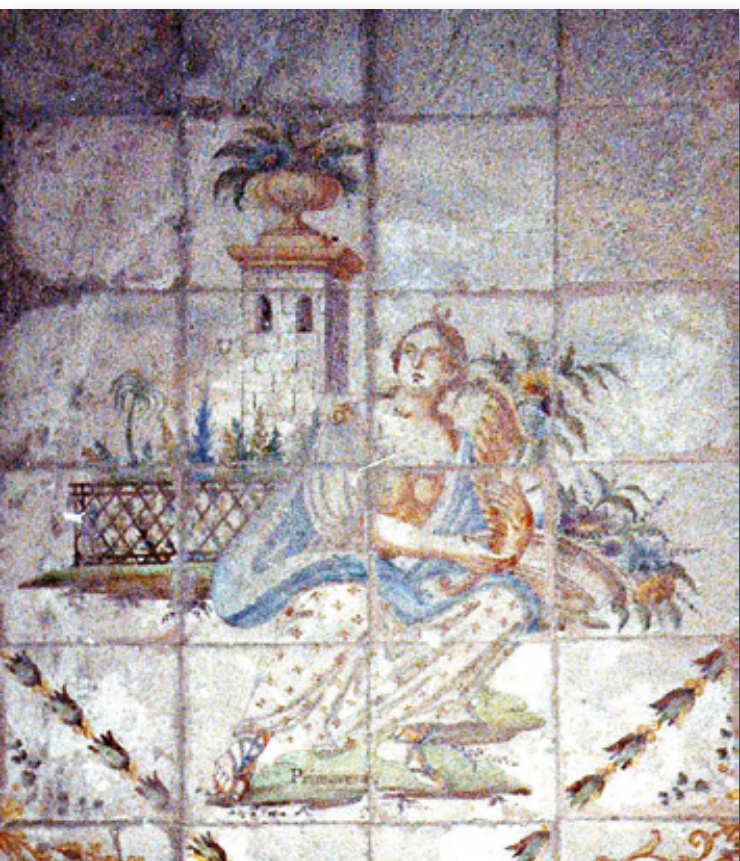

Damunt d'aquestes línies, fig. 2: Antiga Casa badia, Xelva (Fot. J. V. Marés i I. Blasco). A la dreta, fig. 3: Joan Bru. Museu de Ceràmica de l'Alcora.

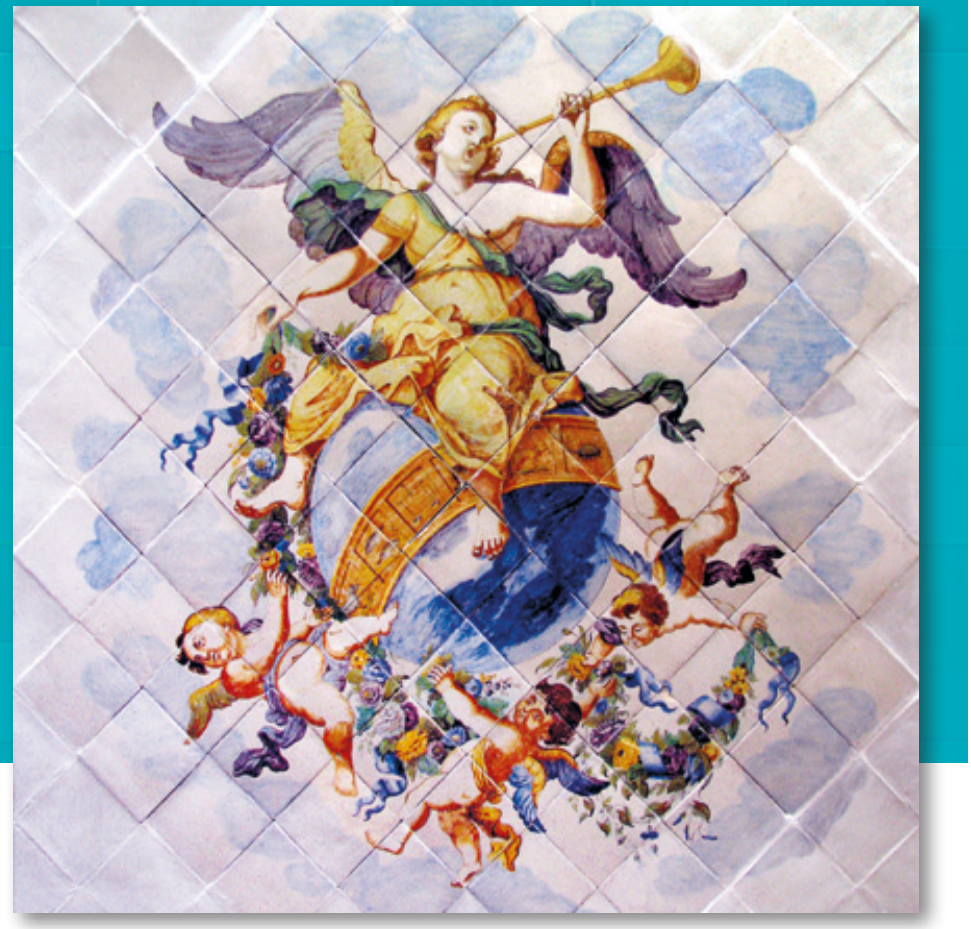

S’incloïen fins i tot directrius mot precises referents a l'acoblament dels taulells:

tres, datades el 1785, s'han conservat al Museo Canario (Archivo del Museo Canario. Colección documental José Miguel Alzola, C. 83) i Alzola les publicà fragmentàriament (Alzola, 2007; Cebrián i Navarro, 2009: 29-30). Els taulells s'embalaven - amb palla d'arròs per a protegir-los- en basquets, caixes o fardells, seguint l'ordre de muntatge. El revers de cada taulell tenia una numeració correlativa que indicava la posició de cadascun en la composició, i els que formaven part d'una mateixa escena portaven, a més, una senyal o lletra distintiva. Si la composició era simètrica es diferenciaven també al dors els de l'esquerra i la dreta. Per a les escenes de més dificultat s'especificava cada pas:

Se pondrá de $n^{0} 1$ á 14 en ylera, y en el del n 15 se empezará otra ylera debajo de la primera, pero dos azulejos antes de llegar al del $n^{\circ} 1$, de modo que el del $n^{\circ} 17$ ha de estar debajo el del n¹, y se seguirá la ylera hasta 32, y así irá siguendo hasta 371. Segun va demostrado en la quadricula grande, y numerado al dorso de ella, de modo que para la mayor perfección y facilidad para pararlo, en cada quadrico de la quadrícula se ha pintado lo mismo que ay en el azulejo, y al dorso tiene el número que le corresponde.
Deven mojarse los ladrillos al asentarlos para que el material agarre y se pegue mejor. Deven ponerse unidos quanto sea posible, que parezca una pieza, y para esto, si hay algun granito de tierra, se quita con paleta, ó cuchillo, ó se restriegan unos cantos de ladrillos con otros; pues quanto más unidos es mejor la vista. Para cortarlos sin desgracia se señalará con lápiz por la cara del verniz. Este se va picando con algun hierro y golpe pequeño, de modo que haga saltar por la misma linea, ó raya, sin que se descascare de uno y otro lado, en ahondando un poquito el canal, con un golpecito contra cosa esquinada se parte por dicha señal. Digo todo mercedes no tomen pesar alguno.

El sistema complex de senyals pintats amb manganès al revers dels taulells ha estat estudiat en detall en el paviment de Les Tres Gràcies del Museu Arqueològic d'Alacant, sorgit també de les fàbriques dels Disdier (Castells i Llopis, 2013: 44-51), de manera que es poden contrastar les indicacions escrites donades a Canàries amb una obra que mai no s'arribà a obrar i roesto porque deseo el acierto y que vuestras 
man intacta, tal com va eixir de la fàbrica, mostrant amb tota claredat el dors de cada peça.

De la significació que tingueren aquestes obres al llarg del segle XIX ens parlen algunes descripcions de paviments realitzades en aquella centúria, en alguns casos quasi coetànies a la fabricació o instal-lació.

Una menció bastant succinta la llegim en l'informe de la Reial Societat Econòmica d'Amics del País de València, feta a partir d'una visita a la fàbrica de Marc Antoni Disdier el 1795. Allí veieren un pavimenti unes socolades destinats a l'Havana i elogiaren els dissenys inspirats en les lògies de Rafael (http://hdl.handle.net/10251/19302). No especifiquen més dades, però és indicatiu del trencament amb l'estil anterior rococó i ens anticipen l'esdevenir neoclàssic de la taulelleria a partir d'aquest moment. Un classicisme entès al voltant del Cinquecento en la majoria dels casos, més que en l'Antiguitat directament.

En el últims anys del segle XIX l'enginyer Rafael Valls descrivia en to laudatori l'obra de Josep Sanchis i Cambra, quan el pintor dirigia la fàbrica valenciana de Royo (Valls, 1894: 136139) a partir de la dècada dels anys 20 , després d'haver passat per les Reials fàbriques:

De los talleres de la fábrica de azulejos del Sr. Royo, en Valencia, salieron hermosas composiciones firmadas por el pintor Sánchiz, en cuyos azulejos no sólo debemos admirar los artísticos paisajes y asuntos mitológicos pintados con sólo cuatro ó cinco colores, que era toda la riqueza de paleta que en aquel entonces podían disponer, sino el verdadero conocimiento que poseían en el resultado que debían dar a los colores después de haber sufrido la cochura para que imitasen con propiedad los paisajes de la Naturaleza [...] Por lo tanto son dignos de figurar en un museo los pavimentos ó pisos en azulejos pintados por el mencionado artista Sánchiz, tanto por su composición, corrección de dibujo y colorido, que hoy se encuentran adornando el salón del piso principal de la casa situada en la calle del Pié de la Cruz, núm. 15, como por la fabricación, pues si dichos azulejos han sido colocados á principios de este siglo, más tarde levantado el piso para reformar la casa, y luego vuelta otra vez á colocarlos, y hoy continúan intactos después de haber sufrido millares de pisadas y golpes, bien podemos asegurar que si estos azulejos hubieran sido fabricados con los procedimientos modernos, de seguro hace años no quedaría de ellos ni el barniz ni los colores. Hermoso es el piso en azulejos del cual nos ocupamos, pero no es menos artístico otro piso en azulejos, pintado también por Sánchiz y colocado en la casa número 9 de la calle de Santa Teresa, el cual, aunque pintado más modernamente, pues fue colocado en año 1831, también es digno de estudio para los pintores ceramistas modernos, puesto que el Sr. Sanchiz, no disponiendo más que de cuatro ó cinco colores, pintó un hermoso y artístico medallón central rodeado de una guirnalda y en las cuatro cartelas cuatro fruteros llenos de fruta valenciana, y en uno de ellos un melón, empezado á cortar la primera raja, con tal naturalidad dibujada y colorido apropiado, que más parece melón colocado en el centro de una mesa y á punto de comerle que no colocado en el suelo para servir de pavimento.

Efrén Beltrán parla en 1898 de la pintura de Miquel Mollà i ens presenta un paviment obrat en la residencia del seu pare (Cebrián i Navarro, 2014: 88), un edifici situat molt prop de l'antiga Casa de la Ciutat de València i que fou enderrocat:

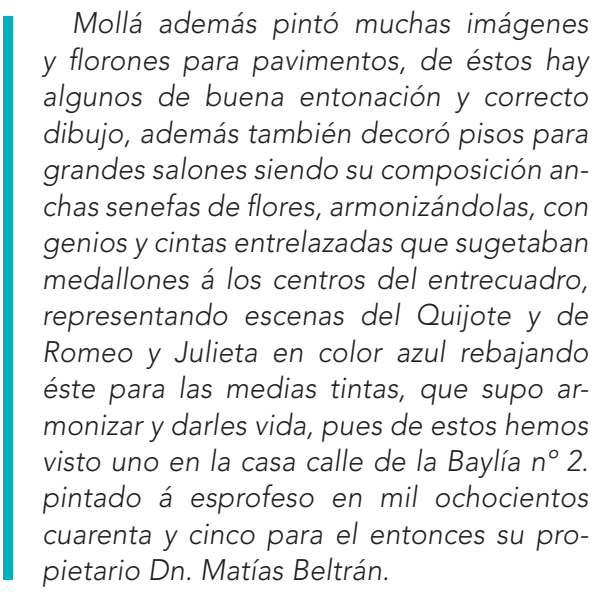

Els paviments que recollien escenes de la novel.la de Cervantes feren fortuna en l'època.

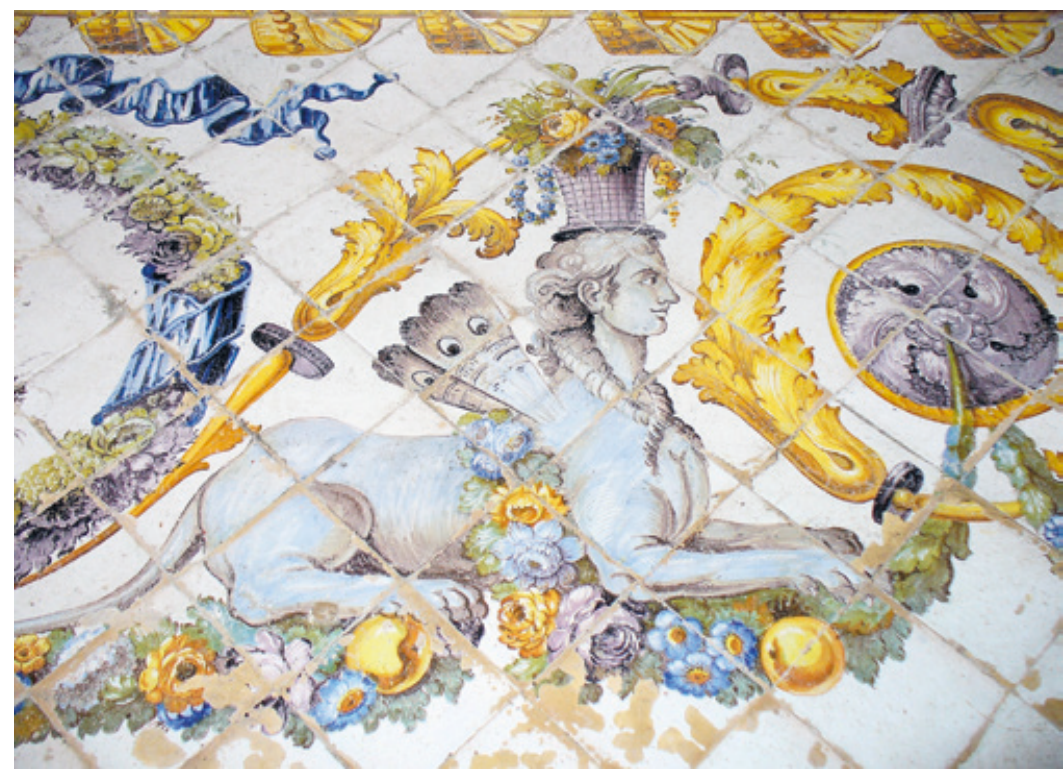

Fig. 4: Joan Bru. Sala capitular, Seu de Saragossa. 
En trobem diversos, com per exemple el fragment que es conserva al monestir de Sant Jeroni de Cotalba, a Alfauir. També resolt amb blau de cobalt i format per 12 taulells $(4 \times 4)$ disposats de cairó, narra l'atac del Quixot al ramat d'ovelles dels pastors. Per les característiques pictòriques i estilístiques, l'atribuïm al pintor Joan Ortiz, actiu als anys centrals de la centúria.

Ressenyem a continuació alguns paviments conservats que serveixen de mostra per tal de veure l'evolució estilística i tècnica, així com el canvi de gusts amb el pas del temps. Les mostres que presentem abasten des de finals del segle XVIII fins als primers anys del segle XX.

Monestir de Portacoeli, Serra. Paviment de la sagristia (fig. 1, pàgina 23). El paviment s'inclou dins de les grans reformes classicistes dutes a terme a finals del segle XVIII a l'església, el rerasagrari i la sagristia, producte de l'apogeu econòmic del cenobi. L'obra de l'església començà en 1770 i s'allargà fins 1780, any d'acabament de les obres segons s'indica a l'emblema de l'entrada fet amb marbres incrustats. El rerasagrari finalitzà vers 1784 segons la data pintada en una de les finestres i a partir d'aquest any començarien les obres de la sagristia (Fuster, 2012: 484-505). El paviment de taulells s'obraria en finalitzar l'obra.

$\mathrm{Al}$ centre veiem tres plàteres formades per cercles concèntrics disposades longitudinalment, de les quals la del mig està més orna- mentada. Apareix circumdada per dos busts alats amb collars i corona de llorer als eixos llargs i dos cistells amb flors als curts. En els cantons, unes victòries amb les ales esteses i florons sobre el cap sostenen l'inici de la sanefa de roleus a base d'elements classicistes: màscares amb ales de papallona, garlandes de perles, fulles d'acant i flors, i cintes tèxtils en ziga-zaga. Tot vorejat per una sanefa exterior de taulells de mostra del mateix estil. Destaca per l'ús de la monocromia groga per a la majoria dels elements.

Amb la introducció del neoclassicisme els paviments prendran una estructura compositiva molt racional i diàfana, fins i tot esquemàtica, com aquest que estudiem, i es deixaran bastants espais sense decoració. De fet, dels aproximadament 680 taulells que componen el pis de la sagristia, uns 395 estan pintats i els restants 285 són blancs.

Elaborat a l'obrador de València de Marc Antoni Disdier, amb una cronologia al voltant de 1785-1790, es pot posar en relació amb els paviments del cambril de l'ermita de la Mare de Déu de la Consolació de Montealegre del Castillo a Albacete, malgrat la composició tèrbola d'aquest, especialment pel que fa als fins roleus daurats, la decoració floral, els cistells i les màscares, tot del repertori classicista. També trobem analogies amb el paviment del cambril de l'església de Santa Caterina de Cabdet, Albacete, i amb l'esmentat de la catedral de Les Palmes de Gran Canària, tots amb datació propera i idèntica procedència fabril. I tots obrats amb les peces seguint la línia dels murs, quan general-

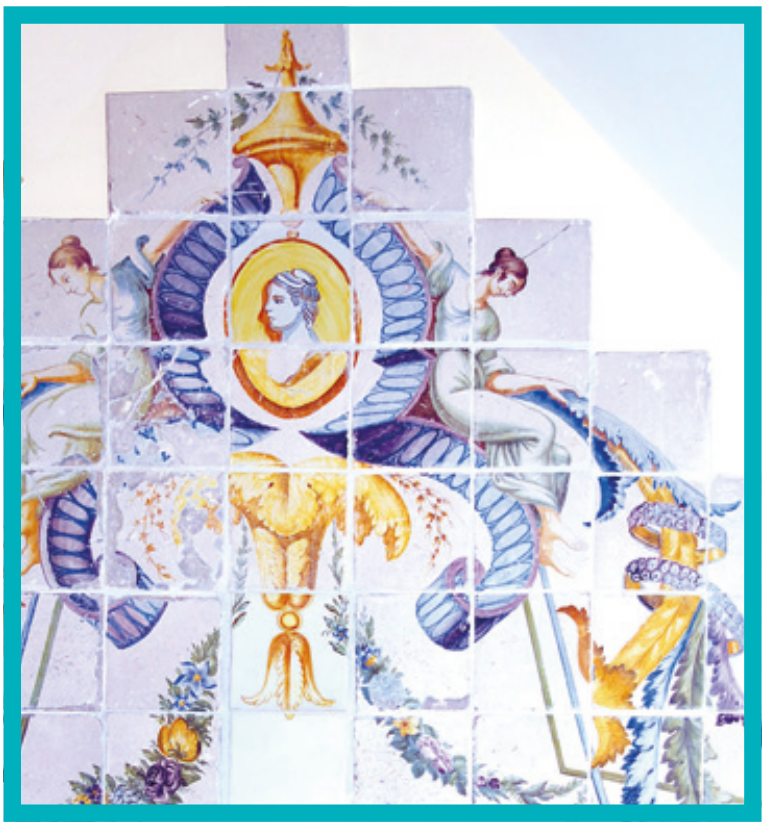

Imatge superior, fig. 5: Josep Sanchis. Església de Sant Joan de l'Hospital, València. A la dreta, fig. 6: Palau de la marquesa de Montortal, Xàtiva.

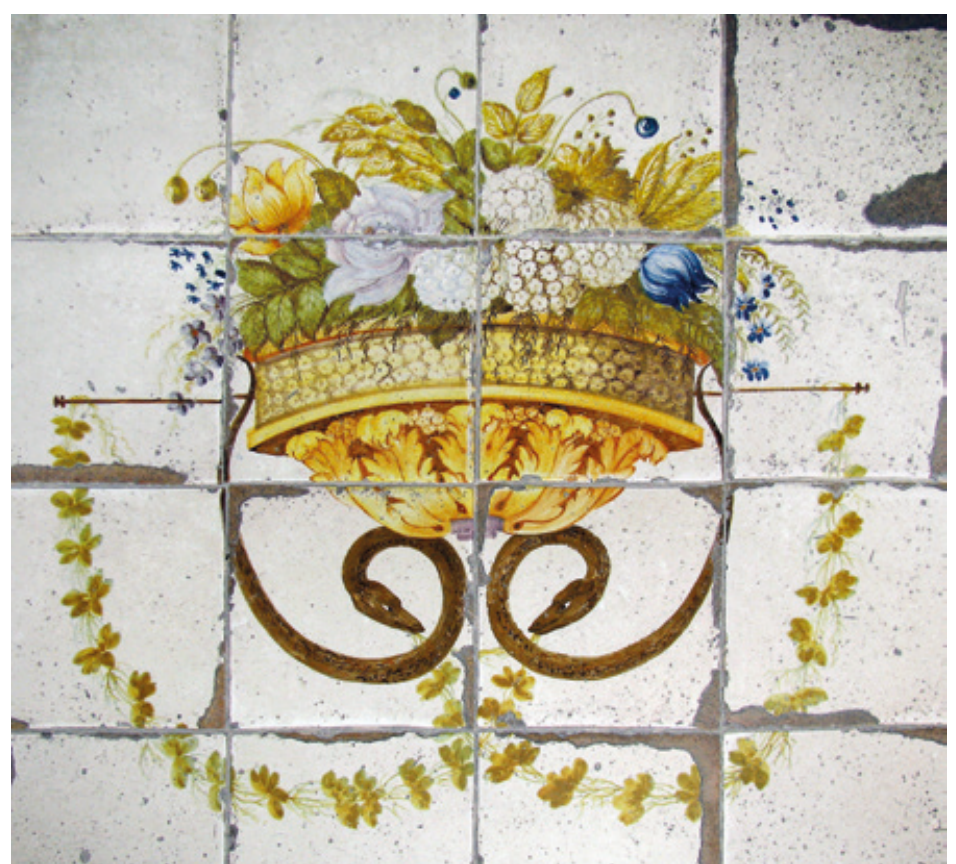



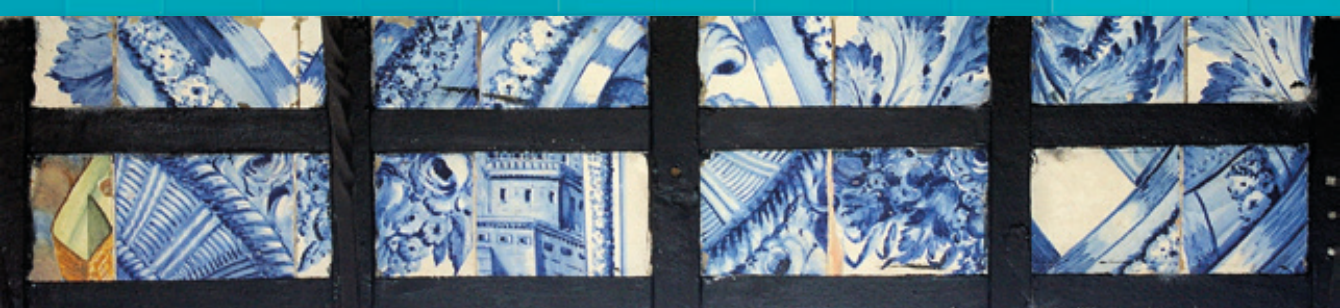

ment els taulells es disposen en diagonal per tal d'evitar la distorsió visual de les línies paral-leles. Es tracta de paviments que anuncien la fi del rococó i
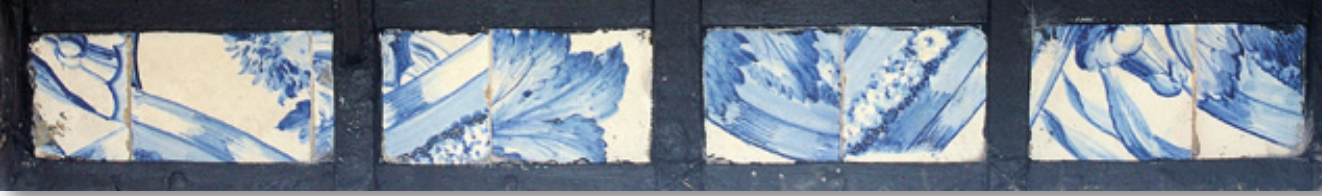

Fig. 7: Volada de balcó, Museu Arqueològic d'Alcoi. l'inici del classicisme que veiem a Portacoeli.

La mateixa mà que pintà el paviment de Portacoeli la identifiquem en una socolada, més tardana, de l'església de Sant Martí de València, especialment si comparem els rostres daurats amb llorers de Serra amb els de la capital, amb similituds tècniques i formals evidents.

La tipologia i funció concreta de la sagristia - no es tracta de salons de palaus o casals-, provoca que l'erosió es concentre en el lateral on se situa la calaixera. Als peus d'aquest moble que guarda la roba litúrgica el desgast és bastant fort, mentre que a la resta del paviment la capa pictòrica es manté en bones condicions.

Antiga Casa badia, Xelva, carrer de María Antonia Clavel (fig. 2, pàgina 24). Pintades als escaires trobem les al-legories de les estacions de l'any, amb el rètol indicatiu de cadascuna. El tema, compost per quatre escenes, com també els quatre continents, resulta idoni per a la superfície quadrangular de les estances d'àmbit privat. Un exemple posterior, classicista, el trobem al paviment de la casa dels López de Vizcaya del Museu de Belles Arts de Múrcia.

Les figures estan voltades per una sanefa exterior formada per la combinació de dos models de taulells de mostra amb el motiu disposat en diagonal. En un d'ells veiem una línia de campanetes de fulles de llorer i branquetes fines amb fulles i fruits. L'altre conté roleus daurats amb flors. Els dos models s'acoblen a partir d'uns quarts de margarida pintats als angles, de manera que resulta una orla ampla i compacta.

Probablement fou pintat a les Reials Fàbriques de València vers 1800. El pintor, artífex de qualitat de nom desconegut, té obra nombrosa. De la seua mà són també les dues socolades de l'església de la Mare de Déu dels Àngels de Xelva amb dos miracles de sant Francesc Xavier i l'exaltació de l'eucaristia amb l'anagrama IHS. Les escenes es mostren dins de cartel.les sostingudes per esfinxs i copes amb ramells al més

pur estil classicista. Els dos treballs, paviment i socolades, haurien estat encarregats de forma paral-lela per la parròquia.

\section{Casa de Diego, Xàtiva. Paviments de la} Fama i de les Muses. L'immoble fou construït per l'arquitecte franciscà fra Vicent Cuenca i els paviments foren pintats per Joan Bru i Plancha a les Reials Fàbriques de València en la primera dècada del segle XIX. És tracta d'un conjunt unitari que ocupa tot l'edifici. Comprén el saló, l'habitació, els balcons i fins i tot els frontals de les escales. Al bell centre de la sala gran s'hi representa la Fama sobre el globus terraqui acompanyada de tres putti que sostenen garlandes de flors i cintes. L'escena potser representa una al-legoria de la fama del propietari de la casa, igual que hem vist en èpoques anteriors, com al Renaixement. La sala rectangular està voltada per una sanefa amb roleus vegetals, perles, copes, etc. del repertori neoclàssic. El motiu central de la Fama és idèntic al conservat al Museu de l'Alcora (fig. 3, pàgina 24), pintat també per Bru a les Reials Fàbriques de taulells de València.

Al dormitori es desenvolupa un programa iconogràfic que relaciona pis, murs i sostre, tot referit a les muses de la mitologia clàssica. Al paviment trobem una escena del Parnàs amb Apol-lo, dempeus amb una lira i la túnica enlairada, acompanyat de quatre muses assegudes als costats. Pels atributs que tenen, n'hem identificat tres: Euterpe, Urània i Talia o Melpòmene. Una sanefa, igual que a la sala, recorre les vores del sòl. Als tres balcons es despleguen roleus vegetals a partir d'uns motius centrals: una escena lacustre, una xineria i una màscara. Destaca el repertori d'ocells i papallones repartits entre la vegetació (Navarro, 2009: 171-172).

Lobra de Xàtiva està molt pròxima, per les relacions estilístiques, formals i tècniques, als tres paviments de l'ermita del Remei d'Alcanar, de mateixa autoria i procedència fabril. Algunes 

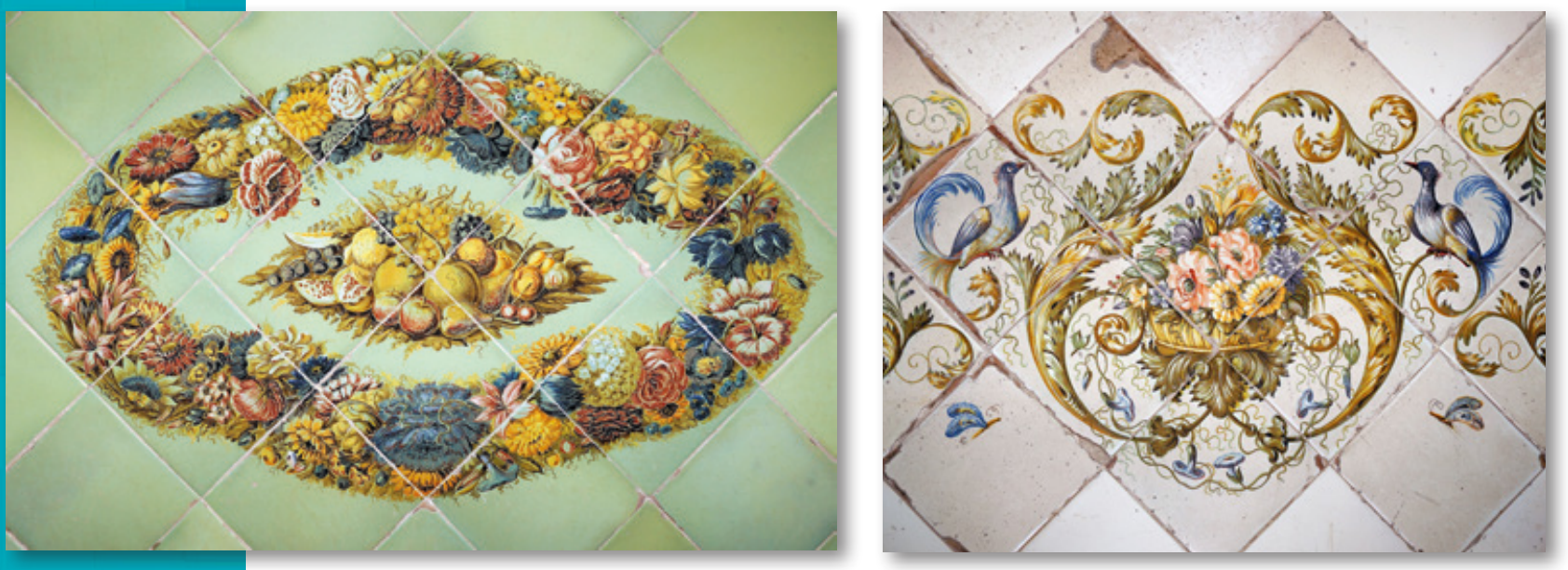

Fig. 8 (a l'esquerra) i 9: Casa Lluís Guarner, Benifairó de les Valls.

escenes dels frontals de les escales de la casa de Diego es repeteixen, ampliades, als medallons del paviment de la Seu de Saragossa, també pintat per Bru (Cebrián i Navarro, 2009: 31-33).

Seu de Saragossa. Paviment de la sala capitular (fig. 4, pàgina 25). Obra signada per Joan Bru, un dels millors pintors de la taulelleria valenciana, a les Reials Fàbriques de València, dirigides per Maria Salvadora Disdier el 1808, segons es llegeix a la inscripció fragmentària (Navarro, 2009: 172).

El disseny del conjunt parteix d'una plàtera central i es desenvolupa en dos eixos de simetria que articulen el gran espai rectangular, subdividit en altres tres rectangles. Tot està voltat por diverses sanefes entre les quals la més complexa és l'exterior. Aquesta conté esfinxs, medallons amb paisatges $i$ als angles figures alades fitomorfes presidides por una florera, tot articulat per roleus d'acant i garlandes de flors i fruites. S'hi palesa la influència dels dissenys de Jean Le Pautre, evident en la disposició bigarrada de la decoració i en els motius triats, elements tots que es poden rastrejar als llibres de l'autor francès. En canvi, alguns paisatges s'inspiren en els gravats de Jean Baptiste Pillement. Es tracta d'escenes monocromes -ocres i marrons- de caràcter romàntic i bucòlic amb predomini de marines, arbredes amb personatges i ruïnes arquitectòniques. Bru fa un ús savi dels colors en combinar la policromia amb elements monocroms o bicroms que harmonitzen el disseny. Per exemple les corones de flors pintades en groc daurat, els esfinxs en blau clar, la garlanda morada que recorre tot el paviment, en contrast als ramells florals

Algunes de les escenes es repeteixen als frontals d'escala de la Casa de Diego, com el que presenta ruïnes, una soca d'arbre i un sarcòfag en primer terme, que sembla basat en la tomba de Marc Agripa de Piranesi. Las garlandes de manganès que recorren el sòl i les que emmarquen els paisatges ovals son idèntiques a la que veiem a la Batalla de Lepant de l'ermita del Remei d'Alcanar, obra autògrafa de Bru realitzada a les mateixes fàbriques (Cebrián i Navarro, 2010).

El paviment aragonès tindrà influència en obres posteriors com podem apreciar al paviment blau de Diana i Apol.lo conservat al Museu del Taulell d'Onda, obra que hem atribuït al Pintor de la Conquesa, artista de les Reials Fàbriques, i en la qual també hi trobem roleus, esfinxs, paisatges, etc. Però en qualsevol cas foren elaborats vers 1830 i estan bastant lluny de la qualitat del paviment de Bru (Cebrián, 2013).

\section{Església de Sant Joan de l'Hospital, Va- lència. Paviment de Josep Sanchis (fig. 5,} pàgina 26). Al mur d'una sala annexa al museu del temple es conserven les restes d'un paviment que en origen no pertanyé a cap estança del complex, sinó que és fruit d'una donació. S'hi mostra el que seria la sanefa exterior en estat fragmentari, amb alguns taulells nous, composta per cintes, fulles d'acant, corones i garlandes vegetals i dues línies en ziga-zaga que aporten cert geometrisme a la composició. Als laterals se situen unes copes amb flors i branques mentre que als escaires s'adapten figures femenines de perfil abillades amb túniques verdes d'estil Imperi. Aquestes estan reclinades sobre uns camafeus voltats per ornamentació tèxtil a mode de frontó arquitectònic curvilini, estructura que sembla inspirada en última instància en les al-legories de Miquel Àngel per a les tombes de Lorenzo i Giuliano de Medici. Novament el model a seguir prové del Cinquecento, com les lògies de Rafael que inspiraren el conjunt destinat a l'Havana.

Pintat sens dubte per Sanchis i Cambra, seria elaborat durant els primers anys del segle XIX 
a les Reials fabriques de taulells de València. Utilitza el mateix model humà que veiem en la mestressa amb granera de la cuina del palau de la marquesa de Montortal a Carcaixent, concretament en l'escena amb el proveïdor galant ( $\mathrm{Na}-$ varro i Cebrián, 2011: 117). Les garlandes florals són idèntiques als pomells de les vares florides que pinta als diversos plafons dedicats a sant Josep. Destaca pel cromatisme viu i intens que acostuma a usar Sanchis.

Palau de la marquesa de Montortal, Xàtiva. A l'edifici es conserven dos paviments vuitcentistes. Un d'ells, elaborat amb molt de raspat, perfilat abundant i colors cridaners, presenta cartel-les ovals als angles que contenen xineries i estan vorejades per una garlanda de grans flors sostinguda per aus aquàtiques i coronat tot per una copa d'or. L'obra és atribuïble a Vicent $\mathrm{Ca}$ marlenc, pintor que també sembla ser l'autor d'un altre paviment de la mateixa ciutat localitzat en l'edifici que allotjava l'històric comerç de la Botiga de Sant Josep on veiem cintes, motlures geomètriques, pebeters amb flames, garlandes vegetals, aus, vasos metàl-lics amb ramells de flors, i unes cartel-les amb un xiquet juganer sobre una illa flotant en l'espai.

L'altre paviment del palau té més qualitat, tant pictòrica com tècnica (fig. 6, pàgina 26). Resolt amb colors suaus aplicats amb pinzellada tènue i continguda, sense gens de perfilat de manganès, ofereix un conjunt harmoniós i amable. Hi ha pintades unes plàteres de metall daurat als angles que contenen abundants varietats florals. La sanefa es completa amb garlandes de petites fulles, cintes blaves, papallones i ocells revolotejant, plomes de paó reial i corones de llorer enllaçades per una cinta ondulant i ovals amb personatges que semblen evocar la conquesta d'Amèrica. Les safates que estan sostingudes per dues serps simètriques enroscades, foren un motiu d'èxit que es repeteix, amb variants, en diversos paviments. És el cas del pis de l'antic palau dels marquesos de Salinas de Múrcia (Jorge, 1961: 3940), ací amb cistells de vímet en lloc de metall.

Museu arqueològic d'Alcoi. Paviment reutilitzat als sotabalcons (fig. 7, pàgina 27). L'edifici que ocupa el museu fou en origen la Casa de la Ciutat. En algun moment, en obrar els balcons s'utilitzaren les restes d'un antic paviment per a les volades. Es tractava d'una obra d'envergadura pintada en monocromia blava, coloració molt utilitzada als paviments elaborats durant els anys centrals del segle XIX, que potser constituí una mena de recuperació de la tradició valenciana de la primera meitat del XVIII on també podríem trobar reminiscències portugueses o holandeses.

Pel que hem pogut recompondre, s'estructura, com la immensa majoria de paviments vuitcentistes, a partir dels eixos bàsics del rectangle que formaria el saló, amb una orla perimetral i un motiu central. La sanefa conté als cantons unes cartel.les octogonals amb panoràmiques urbanes, on es veuen diversos edificis amb teulades a dues aigües, torres i muralles. Al centre de cada un dels quatre costats unes cistelles de vímet contenen flors. Tot unit per garlandes vegetals, cintes i motlures ornamentals. És possible que aquests taulells formaren part del paviment de la sala del Consell de la Ciutat.

\section{Casa de Lluís Guarner, Benifairó de les}

Valls. S'hi conserven dos paviments que en el seu dia adornaren sales privades en la ciutat de València. Ambdós tenen idèntica cronologia, al voltant de 1850-60, estructura semblant i un cromatisme on destaca la tonalitat marró característica de bastants obres del moment. Tenen, a més, la mateixa procedència fabril.

Un dels paviments destaca per l'ús de taulells esmaltats amb verd (fig. 8, pàgina 28), coloració poc usual pel que es dedueix dels paviments que ens han arribat, la immensa majoria amb fons envernissat blanc. Mentre que el vidrat sense addicions resulta una superfície neutra, la policromia aplicada sobre un fons acolorit pot produir certa distorsió a l'hora la visualitzar

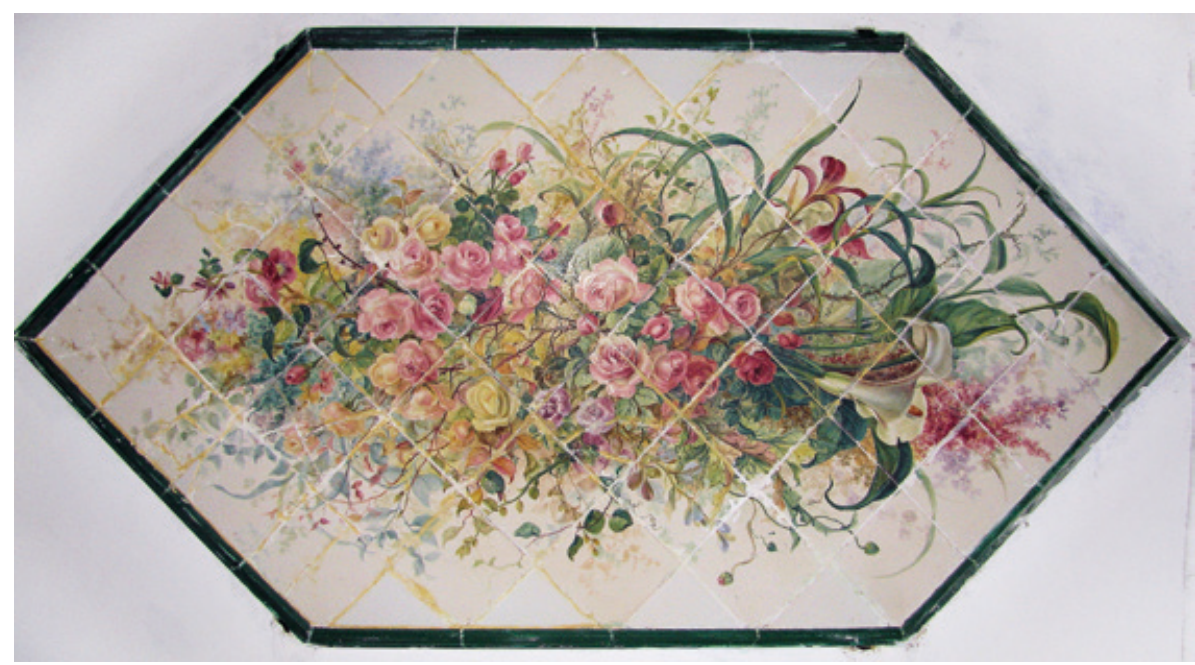

Fig. 10: Francesc Dasí. Monestir del Sant Esperit, Gilet. 

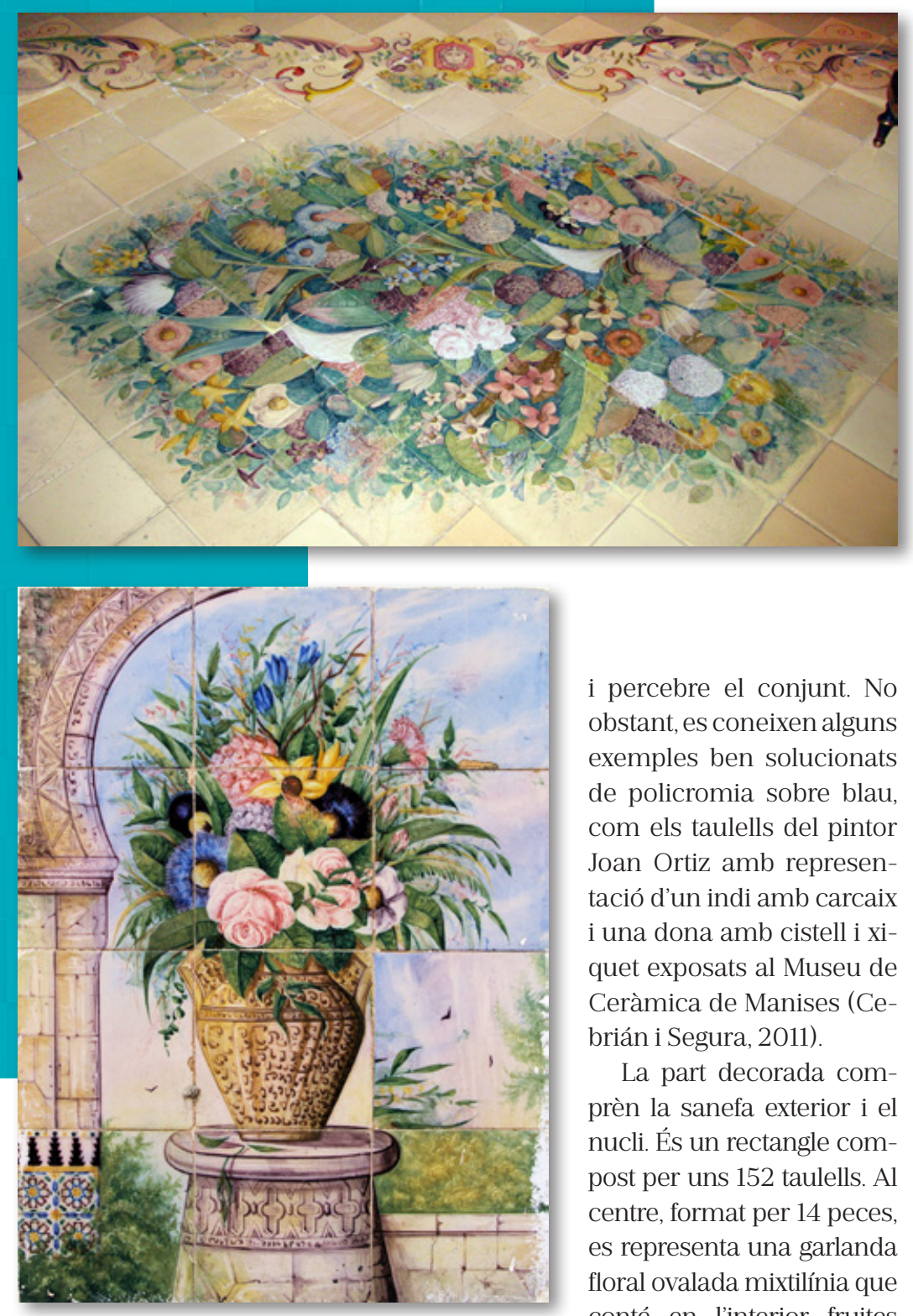

i percebre el conjunt. No obstant, es coneixen alguns exemples ben solucionats de policromia sobre blau, com els taulells del pintor Joan Ortiz amb representació d'un indi amb carcaix i una dona amb cistell i xiquet exposats al Museu de Ceràmica de Manises (Cebrián i Segura, 2011).

La part decorada comprèn la sanefa exterior i el nucli. És un rectangle compost per uns 152 taulells. Al centre, format per 14 peces, es representa una garlanda floral ovalada mixtilínia que conté en l'interior fruites

Imatge superior, fig. 11: Museu Etnològic, Dénia. Davall, fig. 12: Plafó de canterera, colllecció particular.

1. Informació facilitada per Josep A. Gisbert, director del Museu Etnològic de Dénia. variades parades sobre uns pàmpols. Veiem una tallada de meló, raïm blanc i negre, figues, magranes, cireres, peres, bresquilles, albercocs... La sanefa perifèrica conforma l'espai rectangular de $9 \times 7$ taulells disposats de cairó i realitzada amb color verd obscur i blanc que contrasta perfectament amb el fons acolorit del taulell. S'organitza a base de delicats roleus d'acant dels quals neixen unes tiges ondulants amb petites flors blanques i roges de cinc pètals, tot esquitxat de papallones de colors.

Cal destacar la falta de concordança entre el motiu central i l'orla, sense relació estilística ni estètica. Aquest fet ens mostra una altra vessant del procés d'encàrrec i confecció dels paviments. És cert que es tracta de treballs exclusius pel fet que han d'adaptar-se a les dimensions i estructura dels habitatges, però en bastants ocasions, especialment per a estances menors -aquest amida menys de 6 metres-, hi havia diverses mostres ja elaborades a les fàbriques que es podien combinar segons el gust del comitent, a base de mòduls intercanviables. És tracta d'un producte més econòmic, de manera que la petita burgesia també podia gaudir d'aquestes catifes sumptuoses.

L'altre paviment de la casa té el fons blanc (fig. 9, pàgina 28). El nucli, format per 19 peces, és un oval atapeï amb abundant repertori floral, acíamb més varietat cromàtica que en l'anterior. La sanefa perimetral està composta per roleus d'acant, corretjola i papallones. Al eixos veiem uns cistells amb idèntiques flors que al centre flanquejats per dues aus, i als escaires uns vasos de vidre blau amb fruites: magrana, raïm, pera, poma, cireres, figues, entre altres.

\section{Monestir del Sant Esperit, Gilet. Ramell de}

flors (fig. 10, pàgina 29). Es tracta del motiu central, resta d'un paviment pintat per Francesc Dasí. Actualment es pot admirar al mur d'una de les estances del convent. Pertany a l'etapa de maduresa del pintor, a partir de la dècada dels anys 70, caracteritzada entre altres per la delicadesa de la paleta cromàtica, amb ús de colors quasi pastel, aplicada amb pinzellada molt solta al temps que subtil. Els paviments de Dasí assoliren gran prestigi i fama per la qualitat artística, alguns dels quals encara es troben in situ. De fet, el pintor està considerat el millor de la segona meitat del segle XIX, el puntal d'esplendor final de la taulelleria valenciana.

Museu Etnològic de Dénia (fig. 11). El paviment exposat al museu prové de la casa del carrer de Cavallers núm. $14^{1}$. Destaca per la policromia extrema i intensa. Fou elaborat seguint l'estel de Dasí, a imitació dels seus paviments, amb un gran ramell de flors atapeït i una sanefa exterior. Actualment el paviment és un rectangle de $22 \times 9$ taulells disposats de cairó. El pomell central -quasi una enramada - forma un hexàgon de 8 x 5 taulells amb un total de 52 peces.

La sanefa perimetral està formada per roleus de colors assortits que fluctuen a cada pinzellada. Els angles es marquen amb una font amb tritons coronada per una florera. Al centre dels costats llargs veiem una màscara inserida en un una cartel.la daurada amb ferroneries i als eixos dels costats curts uns medallons, tot esquitxat de petits pomells i branques. Està resolt amb abundància de raspats i coloració molt saturada, amb múltiples variacions de tonalitat. Resulta una obra poc naturalista, quasi inversemblant, malgrat que les espècies vegetals són ben reconeixibles. Però és en aquesta artificiositat tan manifesta on rau l'interès i vistositat del paviment. 
D'autor desconegut, podem situar el paviment cronològicament en el període d'entre segles, vers 1900, tant per la tècnica, com sobretot pel cromatisme utilitzat. Una data segura al voltant de la qual podem ubicar el pintor del pis de Dénia és l'any 1903. Es tracta de la data de la restauració que féu l'autor en la socolada del santuari d'Agres, on deixà constància de la intervenció (Segura, 1985). En la sagristia hi ha un fragment de sòcol afegit, amb dues columnes morades jaspiades que tenen garlandes enroscades, a imitació de les existents del segle XVIII, amb les mateixes flors que al paviment de Dénia i amb un rètol inferior on es llegeix: Se renovó esta sacristía en el año 1903.

Del mateix pintor coneixem també un plafó de 4 x 3 en col-lecció particular de Xàtiva, procedent d'una canterera de la Pobla de Vallbona, que conté un gerro sota un arc neoàrab molt del gust del moment, amb idèntiques flors que al paviment denier (fig. 12, pàgina 30). En aquest panell trobem una mostra de taulelleria pintada dins de la taulelleria. A la part de l'esquerra, on arranca l'arc, el pintor de nom desconegut representà els típics taulells neoàrabs que imiten alicatats i merlets escalonats

A més dels paviments d'àmbits privats i de diverses temàtiques, també en trobem d'altres de caràcter religiós en espais públics de culte, i encara que tenen uns significació diferent, foren pintats pels mateixos artistes que els anteriors seguint idèntica tècnica i estil. A l'església de la Transfiguració d'Ibi se n'ha conservat un pintat per Josep Sanchis. Es tracta d'una obra de format oval amb els taulells de cairó que pertanyia al paviment de la capella de la comunió. Actualment el trobem al mur dels peus del temple. És un paviment molt elaborat, de gran qualitat i amb abundants personatges secundaris. L'escena representa l'entrevista entre Abigail i el rei David segons el relat del capítol 25 del primer llibre de Samuel (Cebrián, 2009: 182).

Un altre exemple de paviment religiós és l'escena votiva amb àngels del santuari de la Mare de Déu de l'Estrella de Mosquerola, a Terol. Pintat per Manuel Garcés - de qui sabem que també pintà el paviment de l'altar de l'ermita del Salvador d'Onda, amb l'escut de la ciutat, avui perdut- està resolt en monocromia blava, conté l'any 1858 al filacteri, i fou realitzat a la fàbrica de Novella i Garcés d'Onda (Cebrián i Navarro, 2012: 144).

Aquesta vessant tipològica de la taulelleria -n’és una més entre els plafons devocionals o costumistes, revestiments de cuines, socolades, làpides funeràries, plaques administratives, brancals, panells publicitaris...- que ha gaudit d'una producció extensa al llarg del segle XIX, s'anirà abandonant a poc a poc. Des de finals del segle XIX i principis del XX s'imposarà el paviment de Nollà fabricat a Meliana i sobretot l'hidràulic, molt més econòmics, que acabaran amb els paviments artístics pintats a mà, més costosos. Com diu Efrén Beltrán, l'aparició d'aquestes indústries suposà el colp de gràcia al taulell i la fi de la producció de les "catifes d'estiu".

\section{BIBLIOGRAFIA:}

ALZOLA, José Miguel. (2007). "El pavimento de la Sala Capitular de la Catedral de Santa Ana, de Las Palmas de Gran Canaria". Boletín de Noticias. El Museo Canario, 20: 8-12.

ESCLAPÉS DE GUILLÓ, Pasqual. (2004). [1738] Resumen historial, de la fundación i antigüedad de la ciudad de Valencia. València: Ajuntament de València.

CEBRIÁN I MOLINA, Josep Lluís. (2009). "Josep Sanchis i Cambra: pintura ceràmica devocional”, en Llibre alternatiu. Fira de Xàtiva 2009. Xàtiva: Ulleye, 179-187 i $227-232$.

(2013). "El Pintor de la Conquesta i la Reial fabrica de taulells de Valencia". Recerques del Museu d'Alcoi, 22-23: 107-120.

CEBRIÁN I MOLINA, Josep Lluís; NAVARRO I BUENAVENTURA, Beatriu. (2009). Pintura ceràmica a Xàtiva: plafons devocionals, làpides funeràries i taulells de mostra dels segles XVIII i XIX. Xàtiva: Ajuntament de Xàtiva.

(2010). "El pavimento de la sala capitular de la Seo de Zaragoza". Boletín del Museo e Instituto Camón Aznar, 106: 7-21.

(2012). "Els plafons devocionals de M. Mollà i Manuel Garcés a Jesús Pobre". Aguaits, 31: 131-147.

(2014). Francesc Dasí i la taulelleria valenciana del segle XIX. Xàtiva: Ulleye.

CEBRIÁN I MOLINA, Josep LIuís; SEGURA MARTÍ, Josep Maria. (2011). "Sant Gregori d'Òstia", en Llum de les Imatges: Camins d'art: Alcoi 2011. València: Generalitat, 430-431.
FUSTER SERRA, Francisco. (2012). El legado artístico de la cartuja de Portacoeli. Obras, iconografía, benefactores y artífices en su contexto histórico. Salzburg: Universitat de Salzburg.

CASTELLS GONZÁLEZ, Rosa Ma ; LLOPIS GARCÍA, Teresa Mª . (2013). El pavimento de las Tres Gracias. Colección Beltrán Ausó. Alacant: MARQ.

JORGE ARAGONESES, Manuel. (1961). "Pavimentos decimonónicos de azulejería valenciana en Murcia y su provincia”. Murgetana, 17: 29-57.

NAVARRO I BUENAVENTURA, Beatriu. (2009). "Joan Bru i Plancha: obres a la Costera i la Vall d'Albaida", en Llibre alternatiu. Fira de Xàtiva 2009. Xàtiva: Ulleye, 167-178, 221-226.

NAVARRO I BUENAVENTURA, Beatriu; CEBRIÁN MOLINA, Josep Lluís. (2011). "Més obres dels pintors ceràmics Joan Bru i Josep Sanchis", en Llibre alternatiu. Fira de Xàtiva 2011. Xàtiva: Ulleye, 105-118, 153-168.

SEGURA MARTÍ, Josep Maria. (1985). "Catálogo de los retablos cerámicos de Agres”, en Miscelánea Histórica de Agres. Alcoi: Caixa d'Estalvis d'Alacant i Múrcia, 183-189.

VALLS DAVID, Rafael. (1894): La cerámica. Apuntes para su historia. València: Imp. Juan Guix. 